\title{
Japan's Electricity Trade Logistics Patterns for Our Reference
}

\author{
Shuyuan Wang \\ Jiujiang University, Jiujiang Jiangxi, 332005, China
}

Keywords: E-commerce, Logistics, Mode, Reference

\begin{abstract}
Electronic commerce to soar development trend in recent years become important industry for economic development in our country, the development of electronic commerce led to the rise of the logistics industry, so the improvement of the logistics industry to become the ladder of the progress of electronic commerce in our country. In the process of logistics development in our country not only need to solve their own problems, but also the development experience of other countries for reference, in terms of two aspects of electric business and logistics, Japan is doing better, with the enlargement of the electronic commerce trade market in recent years, Japan has opened a special logistics mode, electricity based on this, this paper starting from the study of Japan's electricity trade logistics mode, explores its enlightenment to our country.
\end{abstract}

\section{Introduction}

Electronic commerce is the important support of the current era of social development, to promote the sustainable development of e-commerce, e-commerce is called for to carry on the consummation to rely on logistics, draw lessons from the development of the advanced experience of other countries, to strengthen the construction of logistics mode and the logistics system, and to forecast the demand of our country's current e-commerce logistics, security can meet the needs of the development of e-commerce logistics.

\section{Japan's e-commerce logistics development situation}

\section{The development situation of Japan's electronic commerce.}

Because of the e-commerce market of Japan has the support of computer science and technology and the Internet. For example, in 2013, Japan's B2C e-commerce market scale in 10.567 trillion yen, compared with last year, increased by $13.5 \%$, thus it can be seen that the Japanese e-commerce market development momentum. E-commerce markets outside Japan, meanwhile, it also had certain development, in 2014 the scale of the B2B electronic market has already reached 30.467 trillion yen, up $18 \%$ on the previous year. On the nature of enterprise, mainly daily department and comprehensive life supermarket e-commerce has a tendency to rise, but the entity shop signs of atrophy of development of industry. Since then, Japan's retail e-commerce enterprises have to catch up with the traditional retail stores. Then according to this development, the need to consider whether Japan's logistics industry can withstand opportunities and challenges, how to implement reforms to meet the current development status is the key problem of the current need analysis.

The matching of Japanese software technology and logistics development.

Japan is a developed country electronic information, make use of information means to manage the logistics, the coordination of the whole process of logistics delivery, in order to implement process management between network and customer service. Japan to enterprise, information management, and form a seamless docking between capital and information, to help enterprises to manage and monitor logistics process, in order to realize low cost and high efficiency of logistics. Logistics information of uninterrupted change promoted the rapid development of electronic commerce in Japan, make the electronic commerce with the support of logistics constantly expand the scale, at the same time the electronic commerce is the logistics industry to meet one of the biggest challenges in today's era, promote the development of logistics industry to realize the specialization, therefore said that the two promote each other and influence each other, realize the highly integrated with each other. 


\section{The matching of Japan's logistics development mode and electronic commerce development pattern.}

Because of traffic lines, facilities, network and a relatively developed, so the Japanese capital Tokyo is the best choice for logistics rally point, which are in high demand for the establishment of large-scale logistics facilities. In recent years, Japan's electronic commerce development rapidly, therefore also has a high requirement on construction of logistics facilities, since 2013, the Japanese capital Tokyo construction of a number of large-scale logistics facilities, this growth is in the lead in the country. Japanese logistics in the development of traditional tend to custody of the item, but the new logistics equipment is different, because the cause of the e-commerce, they pay more attention to the sorting of logistics functions, only do sorting, to promote the rapid work of logistics distribution. At present, in the enterprise of large-scale logistics facilities, more than $50 \%$ of all is the electronic commerce enterprise, and then the manufacturing and other industries, this shows that in Japan, the electronic commerce enterprise is in an important position in national development, the citizen growth played an indispensable role ${ }^{[1]}$.

\section{Japan's e-commerce development impact on Japan's e-commerce logistics}

\section{The development of electronic commerce makes the special logistics emerges.}

Japan's logistics development steps is before the rise of e-commerce, so after take-off, the demand for professional logistics in electronic commerce also gradually to increase. Japan's e-commerce market has a traditional logistics services, and special logistics support, and a lot of logistics facilities more perfect. With the development of computer network technology has realized the electronic commerce, at the same time, in the new logistics facilities, there are a lot of have to be able to provide specialized services for e-commerce enterprise condition, thus, the Japanese logistics facilities are step by step towards bigger size and specialization. It can look from the current development situation, Japan in the 10000 square meters of logistics facilities provide service for the development of electronic commerce ${ }^{[2]}$.

Japan at the beginning of the development of e-commerce in the initial stage, the network order (goods) from the store through the logistics sent to consumers, but along with the rapid development of e-commerce, the increase of product variety, the demand of product features, and so on, this way of logistics have already can't meet the electronic commerce market scale expansion and growth of the order. For this reason, some retail stores in order to be able to solve a large number of order requirements established the virtual shop on the Internet, online order can be done by this shop, this approach compared with the traditional way, largely improved the efficiency of goods distribution, at the same time also appeared the management difficulties. Based on the amazon e-commerce enterprises as an example, every year new logistics facilities around the world in more than 60000 square meters has more than 30, including the construction of the most aggressive in North America, which covers an area of 80000 square meters.

Logistics facilities is consistent with the characteristics of e-commerce logistics distribution.

First, the construction of large-scale logistics facilities need more logistics personnel, so in the construction of logistics facilities should fully consider the humanized design of employees, for example in logistics facilities are equipped with air conditioning equipment, such as the construction of logistics facilities address selection in convenient staff travel site, for example, close to the bus station and parking lot ${ }^{[3]}$.

Second, Japan in order to be able to achieve small batch and high frequency distribution, in terms of logistics configuration power and emergency ability improved, but also for power supply for the emergency.

Third, logistics companies in the sorting of product, to ensure the speed and efficiency, so it will be the best use of the complanation operation space, strive for in the lower floor. Products operating space as far as possible capacious, bright, easy to set up large logistics equipment, in order to realize the automation of logistics operations. Japan in terms of the external environment of logistics facilities to create, to maximize the choice of caring on public transport nodes, which is convenient 
transportation. Covers an area of area will set aside a certain space, used to expand again, so as to meet the needs of e-commerce enterprises growing.

\section{Large-scale development of the environmental impact of logistics facilities.}

In the current development, the massive development of Japanese logistics facilities has high efficiency in use; it is based on large e-commerce market. About 1000 square meters of large-scale logistics facilities in Japan a few, at about 3\%, in Tokyo, the capital of only $7 \%$, so, in this case, the Japanese in the later in the construction of logistics facilities and very big development space. It can be seen in the author's investigation, Japan in the recent five years, by establishing logistics facilities area of 2 million square meters per year on growth, which saw the Japanese development of environmental protection facilities.

Large-scale logistics facilities are in conformity with the actual supply demand forecast.

To analyze the demand of electronic business logistics facilities and can predict the maximum security logistics meet the demand of the growth of e-commerce product order, according to the annual Japanese electronics trade situation and the development of the electronic logistics, to three years from 2015 to 2015, the new logistics facilities in 700000 square meter about a year, from 2009 to 2014, the average supply point of view, each year about 1.5 million square meters is needed to make the balance of supply and demand of logistics and electronic commerce, also can basically meet the conditions of growth. Japan's development of e-commerce, therefore, to a large extent determines the increase the quantity of the logistics facilities ${ }^{[4]}$.

\section{The enlightenment of Japan to our country electronic commerce trade logistics development}

Under the development of e-commerce big stride, strengthen the construction of logistics facilities and professional logistics services.

With the start of China's reform and opening up, especially after China's accession to the WTO, in the environment of global economic integration, our country economy obtained the fast development and promotion, represented by the e-commerce era of the new situation to spring up to introducing a new way of shopping and consumer lifestyle. Electronic commerce development to drive the progress of the logistics industry, in many e-commerce companies "double a" shopping festival, logistics service is faced with new challenges; the electronic commerce to logistics put forward new requirements. For our country according to the above introduction to Japanese e-commerce trade logistics can strengthen the construction of logistics infrastructure, in order to implement e-commerce enterprise logistics system ${ }^{[5]}$.

E-commerce enterprises "11- 11" shopping festival "12-12." this kind of network marketing activities, not just to improve holiday sales, but in this way, let the consumer to understand their own e-commerce sites, from now on to drive sales throughout the year, in order to expand the scale of e-commerce market. The setting of e-commerce professional logistics can not only promote e-commerce market products for transporting efficiency can promote the electricity to raise the level of logistics enterprise management so as to achieve reduce logistics cost, the purpose of improving the quality of logistics service. E-commerce professional logistics construction can speed up to other logistics to the society and the development of professional logistics point the way, which brings to the development of e-commerce enterprises core competitiveness. Thus, need special logistics in electronic commerce in our country make specific deployment, so as to meet the growing e-commerce market demand for logistic.

At the same time, in addition to the electronic commerce logistics, the other part of the traditional logistics industry need to be perfect and improve, this is the development trend of logistics market in China, but also the beginning of logistics specialization, information. With cross-border e-commerce market development, the role of logistics in the system more and more important, thus it can be seen that the construction of the electronic commerce specialized logistics facilities to make our country's logistics industry and international e-commerce market, promote the circulation of the global e-commerce products. 


\section{From the characteristics of electronic business logistics, to the construction of logistics infrastructure.}

Either from the perspective of the logistics system of electronic business enterprise oneself construction or starting from the third party logistics system construction, all need according to the actual situation of e-commerce logistics and distribution characteristics of the city to the perfect scheme for logistics facilities planning and design, in the scheme, as much as possible to meet the needs of the frequency of electronic commerce, we should try to be more frequency, small batch. In logistics warehousing part also need to plan, ensure product no loss, no damage, but also to humane working staff policy formulation, for example, in the sorting operation of logistics, make sure the workplace, work to determine the time, so as to reduce the staff working pressure, maximum avoid because workload is too large, lead to people's physical and mental problems. Strong for the burden of staff must make job security system, under the condition of gradual increase in orders, which wants to do a good job of sorting and transport, which requires on vehicles and personnel equipped with adequate supply. From past, for example, double tenth a logistics, to increase how much, how much more vehicles, etc., so as to protect the interests of the e-commerce companies and safeguard the interests of the consumers.

\section{To e-commerce logistics demand forecast, make it in conformity with actual demand.}

The electronic commerce rapid rise in recent years in our country, thus the development time is not long, the electronic commerce logistics demand analysis and forecast need to collect various data. Measure demand of electronic business logistics to Logistics Company from e-commerce surge is in solving the problem of distribution of a large number of the order. From the perspective of sustainable development, the logistics companies need to plan the construction of logistics facilities, so the logistics demand of measurement can provide certain reference to the logistics company. In addition, forecast the demand of electronic business logistics, can solve the problem of electronic commerce during the festival the accumulated a large number of orders, promote the development of green logistics in our country; minimize excessive pollution of the environment by the construction of logistics infrastructure. For example, each a logistics car will add a point on the local atmospheric environment harms, so before the surge in e-commerce order must to forecast the demand of logistics.

\section{Conclusion}

To sum up, in this paper, the development of electronic commerce to Japan is presented, and then put forward the logistics challenges, in Japan the development of logistics industry and logistics mode of advanced, at the end of the article puts forward how to use for reference the experience of Japan's logistics development in our country, so that the logistics is able to meet the current of the development of e-commerce, enhance economic efficiency, promote the global e-commerce, internationalization development.

\section{References}

[1] Jue Jiangzhenghong, Sun Qianjin. The evolution of Japanese logistics policy - centered on "comprehensive logistics policy implementation outline". China's circulation economy,2010,24(10):4-7.

[2] Weng Xingang, Jiang Xu. The status and enlightenment Japan's green logistics development. China's circulation economy,2011,25(1):16-20.

[3] Lou Yaqiang, Tang Xiangjin, Shen Yan, etc. Japan's revelation to the development of suzhou agricultural cold chain logistics. Value engineering,2015(3):23-24.

[4] Zhang Jingwei. The analysis and enlightenment of Japanese agricultural products logistics development pattern. Journal of rural economy,2011,12(1):126-129.

[5] Jiang Xu. Japanese goods total volume and the pure volume of empirical study. Circulation economy in China, 2010,24(6):23-26. 